\title{
Surface Expression of Secretory Component and HLA Class II DR Antigen on Glandular Epithelial Cells from Human Endometrium and Two Endometrial Adenocarcinoma Cell Lines
}

\author{
ALAN C. MENGE ${ }^{1,3}$ and JIRI MESTECKY ${ }^{2}$
}

Accepted: February 18, 1993

The expression of secretory component (SC) by human glandular endometrial cells cultured in vitro was significantly increased by estradiol in the medium. Interferongamma and interleukin 4 stimulated the expression of SC only in the presence of estrogen. Tumor necrosis factoralpha plus estrogen also caused a significant increase in the number of cells expressing SC. HLA class II antigen DR was detected on few glandular epithelial cells of human endometrium cultured in control medium, whereas interferon-gamma and interleukin- 4 , but not tumor necrosis factor-alpha, caused significant increases in the expression of DR. Estrogen in the culture medium did not significantly affect DR expression. The human endometrial adenocarcinoma cell lines, HEC and RL-95, expressed SC in approximately 50 and $20 \%$ of the cells. Also, approximately $20 \%$ of the RL-95 cells stained for DR antigen. Interferon-gamma did not influence the degree of expression of either surface marker of the two cell lines. Cells of both lines bound polymeric IgA and IgM but showed little to no binding of monomeric $\operatorname{IgA}, \operatorname{IgG}$, or an IgM previously shown not to bind SC.

KEY WORDS: Endometrial cells; cytokines; estrogen; secretory component; DR antigen.

\section{INTRODUCTION}

The female genital tract is one of the organs and tissues that compose the common mucosal immune

\footnotetext{
${ }^{1}$ Department of Obstetrics and Gynecology, University of Michigan, Ann Arbor, Michigan 48109.

${ }^{2}$ Department of Microbiology, University of Alabama at Birmingham, Birmingham, Alabama 35294.

${ }^{3}$ To whom correspondence should be addressed at Department of Obstetrics and Gynecology, L1221 Women's Hospital, University of Michigan Medical Center, 1500 East Medical Center Drive, Ann Arbor, Michigan 48109-0278.
}

system also known as the secretory immune system $(1,2)$. The mucosal immune system secretes more immunoglobulin (Ig), primarily of the $\operatorname{IgA}$ isotype, than the total Ig of all classes originating from bone marrow, spleen, and lymph nodes combined (3). Secreted IgA functions as the first line of defense for the mucosal surfaces. Both serum-derived and locally produced antibodies are found in the cervicovaginal secretions of women (4-9).

An integral part of the secretory immune system is the secretory component (SC), the receptor for polymeric $\operatorname{Ig}(\mathrm{pIg})(10)$. The transport of $\mathrm{pIgA}$ or pentameric IgM, produced by the plasma cells located in the subepithelial tissues, to the lumen of mucosal organs is dependent on the expression of $\mathrm{SC}$ on epithelial cells that binds the pIg on the basolateral surface. The SC-pIg complex is internalized, transported to the apical surface, and secreted into the lumen as S-IgA or S-IgM. Glandular epithelial cells from the human fallopian tubes, uterine endometrium, and cervix have been shown to produce and express surface SC (11-14). The secretion and expression of SC by the endometrium appears to be influenced by the stage of the menstrual cycle $(11,14)$. In addition, adenocarcinomas of the human endometrium also express $\mathrm{SC}$ on the epithelial surface $(11,15)$.

The HLA class II antigen, DR, which is expressed typically on antigen-processing cells, has been also demonstrated on the glandular epithelial cells of the endometrium (16). The expression of SC and DR on some cells and cell lines is modulated by cytokines such as interferon-gamma (IFN- $\gamma$ ), interleukin-4 (IL-4), and tumor necrosis factor-alpha (TNF- $\alpha$ ), all produced by $\mathrm{T}$ cells, suggesting roles 
for these molecules in mucosal immune responses (17-20).

The purpose of the present study was to examine the effects of different recombinant cytokines and estrogen on the expression of SC and DR on glandular epithelial cells from the human endometrium and two cell lines cloned from human endometrial adenocarcinomas.

\section{MATERIALS AND METHODS}

\section{Endometrial Glandular Epithelial Cells}

Samples of normal endometrium were obtained from six women undergoing surgery for nonneoplasic indications. Their age ranged from 35 to 45 years. The specimens were obtained primarily during the proliferative stage of the menstrual cycle. The tissues were maintained on ice until the endometrium was carefully dissected free of myometrium and cut into 5- to $8-\mathrm{mm}$ sections for processing. The tissue was placed in $6-8 \mathrm{ml}$ of $0.2 \%$ collagenase (Type II, Sigma Chemical Co, St. Louis, MO), $0.01 \%$ DNAase (Sigma) in $20 \mathrm{mM}$ Hepes (Sigma)-buffered RPMI 1640 cell culture medium (CM) (Cellgro Mediatech, Washington, DC) (21). Digestion was performed at $37^{\circ} \mathrm{C}$ with constant stirring for $30 \mathrm{~min}$ before the supernatant was replaced with fresh enzyme medium; three or four digestions were done, until the endometrial tissue was completely dispersed. The digested samples were mixed with an equal volume of $\mathrm{CM}$ containing $10 \%$ fetal calf serum (FCS) (Flow Laboratories, McLean, VA) in 15-ml conical centrifuge tubes and placed on ice. After 10-15 min the glands which settled to the bottom of the tubes were removed and resuspended in fresh CM-FCS to repeat the sedimentation process. The fractions containing primarily uterine glands suspended in $10 \%$ FCS in CM were plated in $25-\mathrm{cm}^{2}$ culture flasks (Corning, Corning, NY) for $1 \mathrm{hr}$, which allowed the stromal cells to attach to the plastic surface (22). Epithelial glands did not firmly attach to the plastic surface during that interval. If stromal cells remained in the cell suspension, it was replated again for another hour. The CM containing the glands was removed from the flasks and distributed into a 24-well plate (Corning). The cells were allowed to reach confluency, usually occurring within 3-5 days, at which point treatment with cytokines was initiated. The CM was changed at $48 \mathrm{hr}$ and at the start of the treatments. Estradiol-17B $\left(E_{2}\right)$ (Sigma) was added beginning the first day to some of the cultures at a $10^{-9} M$ final concentration.

\section{Endometrial Adenocarcinoma Cell Lines}

Two cell lines, HEC-1-A and RL95-2, were obtained from American Type Culture Collection, Rockville, MD. The lines were cultured in RPMI 1640 containing $10 \% \mathrm{FCS}, 5 \mu \mathrm{g}$ bovine insulin, 100 $\mathrm{U}$ penicillin, and $50 \mu \mathrm{g}$ streptomycin (Sigma) per ml.

\section{Cytokines}

The cytokines were added to the culture medium at the following concentrations per milliliter: 2002000 U IFN- $\gamma$ (Boehringer Mannheim, Germany), 2 ng IL-4, and 2 ng TNF- $\alpha$ (R\&D Systems, Minneapolis, $\mathrm{MN}$ ).

\section{Immunofluorescence}

The endometrial cells were removed from the wells of the plates by using trypsin-EDTA. After stripping, cells were resuspended in the $\mathrm{CM}$ at approximately $5 \times 10^{6} \mathrm{cells} / \mathrm{ml}$ and $50-\mu \mathrm{l}$ aliquots were pipetted into $1-\mathrm{ml}$ microcentrifuge tubes and placed in a $\mathrm{CO}_{2}$ incubator for $2-2.5 \mathrm{hr}$ to allow reexpression of surface markers (19). The cells were then centrifuged at $200 \mathrm{~g}$ for $4 \mathrm{~min}$, the supernatant removed, and $20 \mu \mathrm{l}$ of labeled or unlabeled antibodies to SC or DR added to each tube. The samples were incubated on ice for $30 \mathrm{~min}$, then washed twice with cold PBS, and if the antibodies were directly labeled with fluorochromes, the cells were fixed with 1\% paraformaldehyde for $20 \mathrm{~min}$, washed with PBS, and mounted on a microslide for fluorescent microscopic observation. Coverslips were sealed using clear fingernail polish. If the first antibody was unlabeled, a second antibody (anti-Ig) labeled with fluorescein isothiocyanate (FITC) or tetramethyl rhodamine isothiocyanate (TRITC) was used with the cells after the wash. The antibodies consisted of the affinity-purified IgG fraction of goat anti-human secretory component conjugated with FITC or TRITC (Dako, Carpinteria, CA), monoclonal antibodies against HLA class II antigen (DR), and anticytokeratin peptide 16 (Becton Dickinson, Mountain View, CA). The second antibody, goat anti-mouse IgG labeled with FITC, was produced in the laboratory of JM. A minimum of 200 cells was counted for 
each labeled preparation. Slides were examined using a Leitz orthoplan microscope (Leitz Co., Wetzlar, Germany) with a superhigh-pressure mercury lamp.

\section{Immunoglobulins}

Human mIgA, pIgA, and IgM were isolated from serum samples of patients with IgA and IgM myelomas and IgG from normal human serum using classical Ig purification methods. $(23,24)$ Ten micrograms of the Ig's was added to suspensions of HEC and RL-95 cells $\left(\times 10^{6}\right)$ and kept on ice for 60 min. The cells were washed twice with cold PBS, exposed to biotinylated-F $\left(\mathrm{ab}^{\prime}\right)_{2}$ antibodies against human IgA, IgG, or IgM (Tago, Burlingame, CA) for $45 \mathrm{~min}$, and washed twice, and then avidin:FITC (Sigma) was added for a 30-min incubation on ice. The cells were again washed, fixed, mounted, and observed as described above.

\section{Statistics}

The data were analyzed by Student's $t$ test and are presented as percentage mean \pm standard error of the mean (SE).

\section{RESULTS}

The cell cultures of the endometrial glands possessed the characteristics of epithelial cells in monolayer, as they appeared polyhedral in shape and arranged in swirls. Upon staining the epithelial cell cultures with the anticytokeratin antibody, more than $95 \%$ of the cells displayed cytoplasmic reactivity.

In the absence of $E_{2}, 6 \pm 3.2 \%$ of the epithelial cells displayed detectable SC on the surface (Fig. 1). The addition of the cytokines IFN- $\gamma$ and IL-4 to the $\mathrm{CM}$ resulted in small and nonsignificant increases in the number of cells expressing SC. However, after adding $E_{2}$ to the medium, the incidence of cells with detectable surface SC increased to 21 $\pm 3.1 \%$. With $\mathrm{E}_{2}$ present in the $\mathrm{CM}$, the addition of the cytokines resulted in a further enhancement in the number of cells expressing SC: the addition of 2 ng of TNF- $\alpha$ increased the percentage to $39 \pm 6.9 \%$ and the combination of IFN- $y$ and IL-4 to $37 \pm$ $3.5 \%$. The combination of IFN- $\gamma$ and TNF- $\alpha$ did not enhance SC expression above that induced by TNF- $\alpha$ alone $(32 \pm 2.5$ vs $39 \pm 6.9 \%)$.

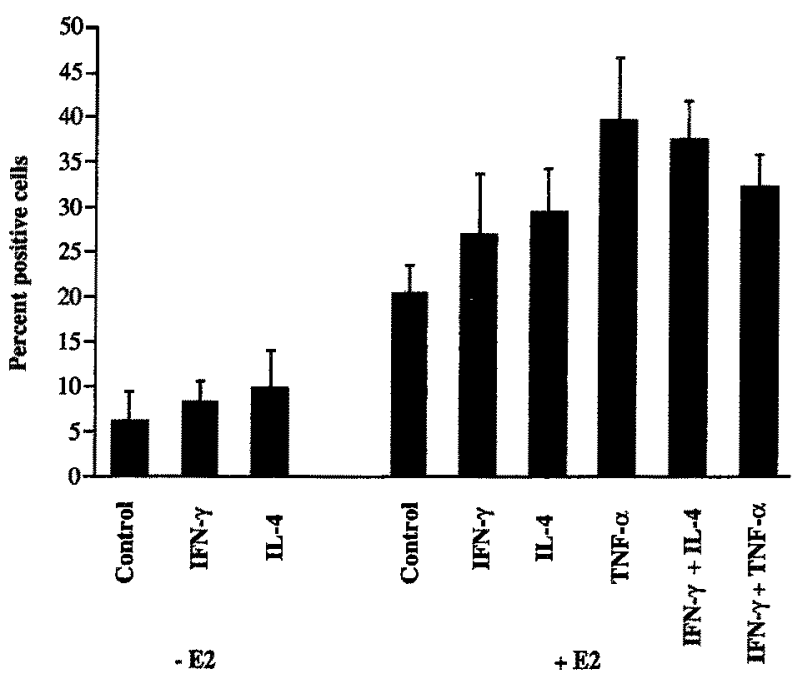

Fig. 1. Expression of SC on endometrial gland epithelial cells modulated by $\mathrm{E}_{2}\left(10^{-9} M\right)$ and stimulated for $48 \mathrm{hr}$ with $200 \mathrm{U} / \mathrm{ml}$ IFN- $\gamma, 2 \mathrm{ng} / \mathrm{ml}$ of IL-4, or $2 \mathrm{ng} / \mathrm{ml}$ of TNF- $\alpha$ alone or in combination. After $48 \mathrm{hr}$ the cells were harvested and labeled with anti-SC antibodies.

DR antigen expression on the epithelial cell surface was independent of the presence of $E_{2}$ (Fig. 2). Less than $6 \%$ of the cells were DR + in the absence of any cytokines or $E_{2}$ in the media. The addition of IFN- $\gamma$ to media without or with $E_{2}$ induced $68 \pm 6.4$ and $68 \pm 8.2 \%$ of the cells to express DR. IL-4 treatment resulted in $53 \pm 5.8$ and $44 \pm 4.1 \%$ of the cells being DR + and TNF- $\alpha$ induced approximately $11 \pm 2.0 \%$ positive cells. In comparison with IFN- $\gamma$

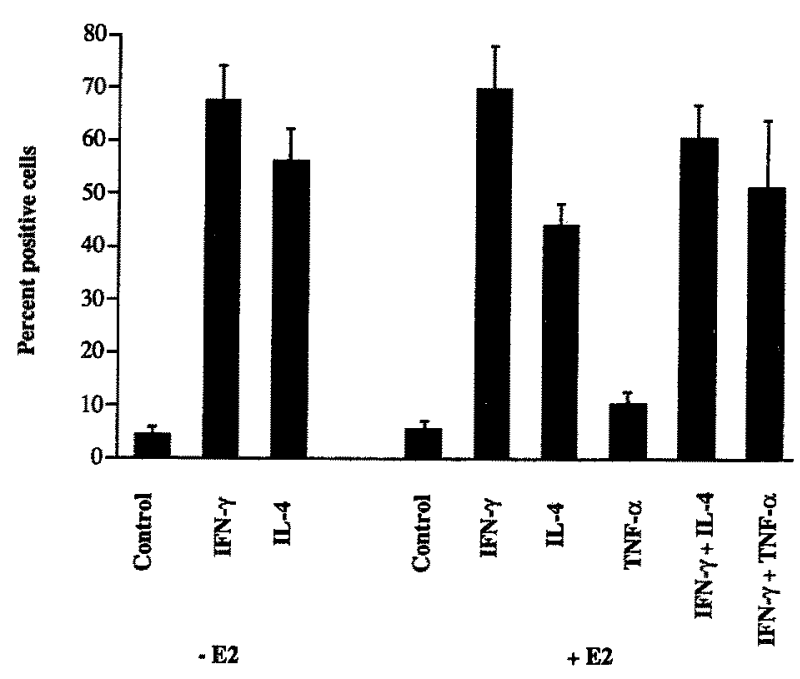

Fig. 2. Expression of DR antigen on endometrial gland epithelial cells cultured without and with $\mathrm{E}_{2}\left(10^{-9} M\right)$ and stimulated for 48 hr with $200 \mathrm{U} / \mathrm{ml}$ IFN- $\gamma, 2 \mathrm{ng} / \mathrm{ml} \mathrm{IL}-4$, or $2 \mathrm{ng} / \mathrm{ml}$ of TNF- $\alpha$ alone or in combination. After $48 \mathrm{hr}$ the cells were harvested and labeled with anti-DR antibodies. 


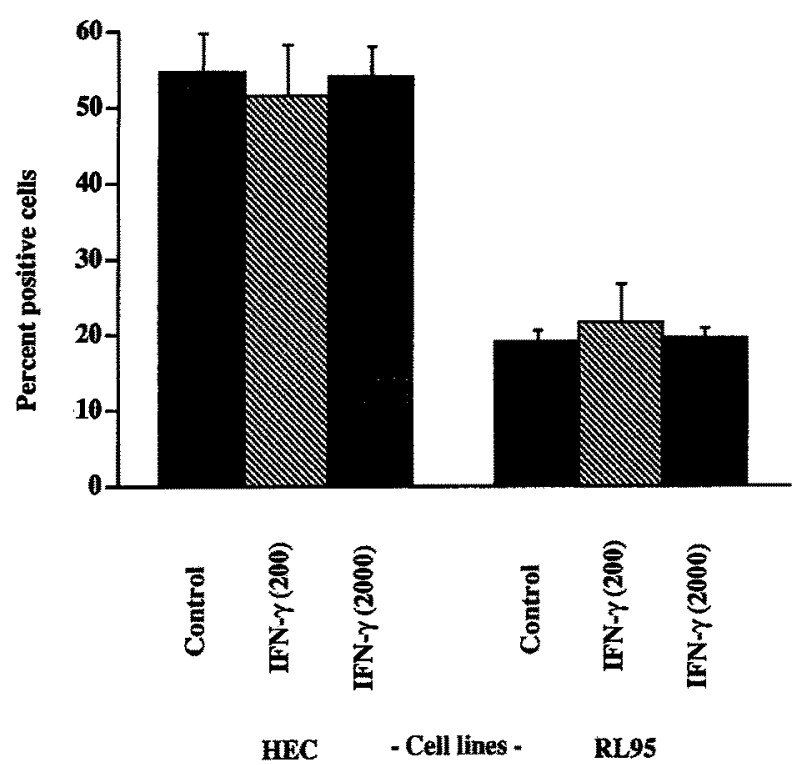

Fig. 3. Lack of influence of IFN- $\gamma$ on SC expression by endometrial cell lines HEC and RL95. Cytokine added for $48 \mathrm{hr}$ before harvesting and immunofluorescent analysis of SC cell surface expression.

alone, the combination of TNF- $\alpha$ with IFN- $\gamma$ or with IL-4 had little effect on DR expression by the epithelial cells. The incidence of epithelial cells coexpressing both SC and DR markers was significantly modulated by the cytokine treatment and the presence of $E_{2}$ in the culture media. In media without $E_{2}, 9-16 \%$ of the total cells positive for either SC or DR were positive for both antigens. With the addition of $E_{2}$ the percentage of cells positive for both markers increased to $29 \pm 4.9 \%$. Addition of the different cytokines to $\mathrm{E}_{2}$-stimulated cells resulted in coexpression as follows: IFN- $\gamma, 33$ $\pm 3.2 \%$; IL-4, $38 \pm 5.0 \%$; TNF- $\alpha, 13 \pm 4.3 \%$; IFN- $\gamma+\mathrm{IL}-4,40 \pm 3.8 \%$; and IFN- $\gamma+$ TNF- $\alpha, 26$ $\pm 6.1 \%$.

The average incidence of cells positive for $\mathrm{SC}$ in the HEC line was $54 \pm 9.7$ and $19 \pm 1.5 \%$ for RL-95 cell line (Fig. 3). The expression of DR antigen was limited to the RL-95 cell line with $21 \pm 2.5 \%$ of the cells being positive at confluency. Staining of the RL-95 cells for SC and DR indicated between 33 and $40 \%$ of the cells expressed both markers. The numbers of cells expressing SC (52.8 \pm 8.3 and 20.5 $\pm 3.1 \%)$ in HEC and RL-95 cell lines or DR ( $25 \pm$ $4.9 \%$ ) in RL-95 cells were not significantly affected by treatment of the cell cultures with IFN- $\gamma$ at 2000 $\mathrm{U} / \mathrm{ml}(n=4)$. All of the cells from both cell lines exhibited cytoplasmic staining with the FITClabeled anti-cytokeratin antibody. Approximately

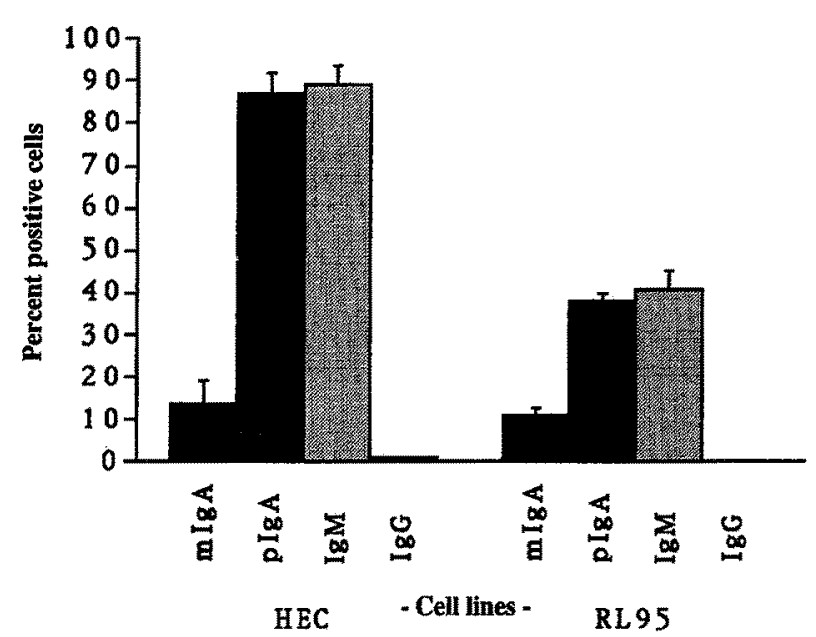

Fig. 4. Binding of human Ig's on cell surface of endometrial cell lines HEC and RL95. Cells were incubated with purified human Ig's, washed, and exposed to FITC-labeled antibodies against the different Ig's.

$25 \%$ of HEC and $80 \%$ of RL 95 cells showed intense cytoskeleton staining.

Binding studies $(n=3)$ indicated that the majority of the HEC cells bound pIgA $(87 \pm 8.7 \%)$ and IgM $(89 \pm 7.9 \%)$ but little mIgA $(14 \pm 5.3 \%)$ and less than $1 \%$ for IgG and a nonbinding IgM (Fig. 4). The percentages of RL-95 cells binding the different Ig's were as follows: $\mathrm{pIgA}, 38 \pm 3.3 \%$; IgM, $41 \pm 7.8 \%$; $\mathrm{mIgA}, 11 \pm 3.6 \%$; IgG and nonbinding IgM, $0 \%$.

\section{DISCUSSION}

The results of our study confirm the report of Tabibzadeh et al. (16) that epithelial cells from the human endometrium respond to the T-cell cytokine IFN- $\gamma$ by the induction of Class II HLA-DR expression on the cell membranes. IFN- $\gamma$ has been shown to also induce DR antigen on the surface of different cell types (18). We report here that IL-4 also increased the level of $D R$ expression on the endometrial cells.

However, expression of SC on the endometrial cells was also influenced by the gonadal hormone estrogen. The effect of progesterone alone or with estrogen was not evaluated in the cell culture system. Immunocytochemical evaluation of SC expression by the human endometrium suggested, however, that secretion occurred throughout the menstrual cycle with maximum expression in the late secretory phase (11). In vivo studies demonstrated the essential role of estrogen in inducing SC production by the endometrium in ovariectomized 
rats (25). Contrary to the reported IFN- $\gamma$ enhanced uterine SC secretion in ovariectomized rats, we did not observe such an increase in human cells cultured in vitro. The percentage of cells expressing membrane SC was shown by Sollid and co-workers (20) to be highly associated with cellular production and secretion of SC using HT-29 human colonic adenocarcinoma cells as a model system.

TNF- $\alpha$ exhibited a differential effect on expression of the two markers on endometrial cells: it significantly enhanced SC expression but showed little effect on DR expression. This was similar to results reported for colonic cell line HT-29 in which SC expression was increased by IFN- $\gamma$ and TNF- $\alpha$ but DR was increased only by IFN- $\gamma(18)$. If the two cytokines were given together a synergistic effect on DR expression was then noted. In addition, IFN- $\gamma$ and IL-4 have demonstrated a synergistic effect on SC secretion by HT-29 cells (19). Inflammation of the gastric epithelial lining also caused an upregulation of SC expression, suggesting a role for the inflammatory cytokines, i.e., IFN- $\gamma$ and TNF- $\alpha$ (26). These two cytokines are products of $T$ lymphocytes and macrophages, respectively, which are found in elevated numbers in inflammed intestinal epithelia.

The two endometrial adenocarcinoma cell lines, unlike the endometrial epithelial cells and the HT-29 cell line, were not noticeably modulated as to the degree of SC and DR expression by IFN- $\gamma$. That the SC molecule on the epithelial cells and the cell lines was functional was in part demonstrated by its binding to pIgA and pIgM compared with the weak to nonexistent binding of $\mathrm{mIgA}, \operatorname{IgG}$, and a IgM known previously not to bind to $\mathrm{SC}$. The incidence of labeled cells increased significantly with the indirect detection of SC after the addition of pIgA and IgM in comparison to direct detection of SC with antibody. This observation was noted previously in a study on HT-29 cells (19). The binding affinity of pIgA for SC was estimated to be approximately two orders of magnitude greater than that of antibody for SC.

The endometrium is a mucosal tissue that is involved in the transport of pIgA and IgM. As in other mucosal tissues and organs, cytokines and hormones can enhance the efferent limb of the secretory immune system through the up regulation of SC production and expression. Epithelial cells from various mucosal tissues may respond differentially to cytokines if regulated by hormones, e.g., mammary glands and reproductive tissues are un- der primary control of the endocrine system reflecting their physiological functions of lactation and reproduction, whereas intestinal epithelia are directly affected by cytokines without the requirement for preconditioning by hormones (1). In the absence of Ig-secreting plasma cells in the endometrium, serum-derived pIgA and IgM may be more important sources of S-IgA and S-IgM than local production. Transport of pIgA from the serum across the respiratory epithelium has been demonstrated in mice $(27,28)$. We observed similar results of the transfer of antibody activity of pIgA from serum into the female reproductive tract of mice (Renegar, Menge, and Mestecky, unpublished work).

\section{ACKNOWLEDGMENTS}

This work was supported by U.S. Public Health Service Grants AI10854, AI28147, DE08228, and DK28537 awarded to JM.

\section{REFERENCES}

1. Mestecky J, Kutteh WH, Ladjeva I, Peterman J: The common mucosal immune system in the human genital tract and mammary gland. In Reproductive Immunology 1989, L Mettler, WD Billington (eds). Amsterdam, Elsevier Science, 1990, pp 251-258

2. Kutteh WH, Edwards RP, Menge AC, Mestecky J: IgA Immunity in female reproductive tract secretions. In Proceedings of the Symposium on Local Immunity in Reproductive Tract Tissues, GP Talwar (ed). Cambridge, Cambridge University Press, 1992, pp 229-243

3. Mestecky J, McGhee JR: Immunoglobulin A (IgA): molecular and cellular interactions involved in IgA biosynthesis and immune response. Adv Immunol 40:154, 1987

4. Archibald DW, Witt DJ, Craven DE, Vogt MW, Hirsch MS, Essex M: Antibodies to human immunodeficiency virus in cervical secretions from women at risk for AIDS. J Infect Dis 156:240-241, 1987

5. Merriman H, Woods S, Winter C, Fahnlander A, Corey L: Secretory IgA antibody in cervicovaginal secretions from women with genital infection due to herpes simplex virus. $J$ Infect Dis 149:505-510, 1984

6. O'Reilly RJ, Lee L, Welch BG: Secretory IgA antibody responses to Neisseria gonorrhoeae in the genital secretions of infected females. J Infect Dis 133:113-125, 1976

7. Richmond SJ, Milne D, Hilton AL, Caul EO: Antibodies to Chlamydia trachomatis in cervicovaginal secretions: Relation to serum antibodies and current chlamydial infection. Sex Trans Dis 7:11-15, 1980

8. Terho P, Meurman O: Chlamydial serum IgG, IgA and local IgA antibodies in patients with genital-tract infections measured by solid-phase radioimmunoassay. J Med Microbiol 14:77-87, 1981 
9. Haas GG: Immunologic infertility. Obstet Gynecol Clin No Am 14:1069-1085, 1987

10. Brandtzaeg $P$ : The role of J chain and secretory component in receptor-mediated glandular and hepatic transport of immunoglobulins in man. Scand J Immunol 139:3961-3969, 1985

11. Arends J, Groniowski $M$, de Koning Gans $H$, Bosman F: Immunohistochemical study of the distribution of secretory component and IgA in the normal and diseased uterine mucosa. Int J Gynecol Pathol 2:171-181, 1983

12. Kelly J, Fox H: The local immunological defence system of the human endometrium. J Reprod Immunol 1:39-45, 1979

13. Kutteh W, Hatch K, Blackwell R, Mestecky J: Secretory immune system of the female reproductive tract. I. Immunoglobulin and secretory component containing cells. Obstet Gynecol 71:56-60, 1988

14. Suzuki $M$, Ogawa $M$, Tamada $T$, Nagura $H$, Watanabe $K$ : Immunohistochemical localization of secretory component and IgA in the human endometrium in relation to menstrual cycle. Acta Histochem Cytochem 17:223-229, 1984

15. Lee Y-S, Raju G: Expression of IgA and secretory component in the normal and in adenocarcinomas of Fallopian tube, endometrium and endocervix. Histopathology 13:6778,1988

16. Tabibzadeh S, Gerber M, Satyaswaroop P: Induction of HLA-DR antigen expression in human endometrial epithelial cells in vitro by recombinant $\gamma$-interferon. Am J Pathol 125:90-96, 1986

17. Kvale D, Lovhaug D, Soolid L, Brandtzaeg P: Tumor necrosis factor- $\alpha$ upregulates expression of secretory component, the epithelial receptor for polymeric Ig. J Immunol 140:3086-3089, 1988

18. Kvale D, Brandtzaeg P, Lovhaug D: Up-regulation of the expression of secretory component and HLA molecules in a human colonic cell line by tumor necrosis factor- $\alpha$ and gamma interferon. Scand J Immunol 28:351-357, 1988
19. Phillips J, Everson M, Moldoveanu Z, Lue C, Mestecky J: Synergistic effect of IL-4 and IFN- $\gamma$ on the expression of polymeric Ig receptor (secretory component) and IgA binding by human epithelial cells. J Immunol 145:1740-1744, 1990

20. Sollid L, Kvale D, Brandtzaeg P, Markussen G, Thorsby E: Interferon enhances expression of secretory component, the epithelial receptor for polymeric immunoglobulins. J Immunol 138:4303-4306, 1987

21. Satyaswareep P, Bressler R, de la Pena M, Gurpide E: Isolation and culture of human endometrium in vitro. J Clin Endocrinol Metab 48:639-645, 1979

22. Osteen K, Hill G, Hargrove J, Gorstein F: Development of a method to isolate and culture highly purified populations of stromal and epithelial cells from human endometrial biopsy specimens. Fertil Steril 52:965-972, 1989

23. Mestecky J, Zikan J, Butler W, Kulhavy R: Studies on human secretory immunoglobulin A. III. J chain. Immunocytochemistry 9:883-991, 1972

24. Mestecky J, Kilian M: Immunoglobulin A (IgA). Methods Enzymol 116:37-75, 1985

25. Wira C, Bodwell J, Prabhala R: In vivo response of secretory component in the rat uterus to antigen, IFN- $\gamma$ and estradiol. J Immunol 146:1893-1899, 1991

26. Valnes K, Brandtzaeg P, Elgjo K, Stave R: Specific and nonspecific humoral defense factors in the epithelium of normal and inflammed gastric mucosa: Immunohistochemical localization of immunoglobulins, secretory component, lysozyme and lactoferrin. Gastroenterology 86:402-412, 1984

27. Mazanec M, Nedrud J, Liang X, Lamm M: Transport of serum IgA into murine respiratory secretions and its implications for immunization strategies. J Immunol 142:42754279,1989

28. Renegar K, Small P: Passive transfer of local immunity to influenza virus infection by IgA antibody. J Immunol 146: 1972-1978, 1991 